\title{
Extreme Ultraviolet (EUV)-Resist Materials of Noria (Water Wheel-Like Cyclic Oligomer) Derivatives containing Acetal Moieties
}

\author{
Hiroto Kudo, Mayumi Jinguji, Tadatomi Nishikubo, \\ Hiroaki Oizumi* and Toshiro Itani*
}

\author{
Department of Material and Life Chemistry, Faculty of Engineering, \\ Kanagawa University, 3-27-1, Rokkakubashi, Kanagawa-ku, Yokoham, 221-8686, Japan \\ * Selete (Semiconductor Leading Edge Technologies, Inc.) Research Dept.3 \\ 16-1 Onogawa, Tsukuba, Ibaraki 305-8569, Japan
}

\begin{abstract}
The synthesis and properties of noria derivatives (noria-CHVE's) with pendant acetal moieties were examined for application as extreme ultraviolet (EUV)-resist materials. The reaction of noria and cyclohexyl vinyl ether was carried out in the presence of pyridinium $p$-toluenesulfonate as a catalyst, to give the corresponding noria-CHVE's with various degrees of introduction (DI) of cyclohexyl acetal moieties by adjusting the feed ratio of reactant and reaction time. The physical properties (solubility, thermal stability, and film-forming ability) of noria-CHVE's were consistent with the differences in DI values. The patterning properties of noria-CHVE $E_{50}(\mathrm{DI}=50)$ and noria-CHVE $\mathrm{CH}_{59}(\mathrm{DI}=$ 59) were investigated in an EUV-resist system, and it was found that noria-CHVE ${ }_{50}$ gave higher resolution than noria-CHVE $\mathrm{E}_{59}$, providing a clear line and space pattern with a resolution of $37.9 \mathrm{~nm}$ and a line-edge roughness (LER) of $7.2 \mathrm{~nm}$.
\end{abstract}

Keywords : noria, acetal, chemically amplification, extreme ultraviolet, resist

\section{Introduction}

New lithography systems employing electron beams (EB) and short-wavelength lasers, such as $\operatorname{KrF}(\lambda=248 \mathrm{~nm})$, ArF $(\lambda=193 \mathrm{~nm})$, and extreme ultraviolet (EUV) $(\lambda=13.5 \mathrm{~nm})$ are expected to produce the higher resolution semiconductor devices, and the development of new photo-resist materials has been strongly required. Among them, photo-functional polymers containing adamantine, norbornene, fluorine atoms, and certain protecting groups such as trimethylsilyl and tetrahydropyranyl groups showed higher photo-sensitivity, lower outgassing, and low line-edge roughness (LER). ${ }^{1}$

Recently, many molecular glass resists based on dendritic oligomers, ${ }^{2}$ calixarenes, ${ }^{3}$ low-molecular-weight polyphenols, ${ }^{4}$ and fullerenes ${ }^{5}$ could show high photo-sensitivity in EB and EUV lithography systems. We have also examined the synthesis and properties of the calixarene derivatives containing photo-degradable groups, such as $t$-butyloxycarbonyl, ${ }^{6}$-butyl ester, ${ }^{7}$ and acetal groups. ${ }^{8} \quad$ As the results, although these derivatives showed excellent photosensitivity, a clearly resolved pattern could not be achieved, due to that the line pattern was broken down during the etching process. ${ }^{9}$ This means that the mechanical property of calixarene derivatives is insufficient to construct the higher resolution patterns. Very recently, we have succeeded the synthesis of a ladder cyclic molecule "noria" (noria $=$ water wheel in Latin) by the condensation reaction of resorcinol and 1,5-pentanedial under dynamic covalent chemistry (DCC) system. ${ }^{10}$ As shown in Scheme 1, the noria derivatives with pendant photo-degradable groups have been examined in the application as EB and EUV resist materials. The noria derivatives containing 
$t$-butoxycarbonyl groups ${ }^{11}$ and $t$-butyl ester groups $^{12}$ showed clear line and space patterns with resolutions of $50 \sim 70 \mathrm{~nm}$ in EB resist system. The noria derivative containing adamantate groups could show clear line and space patterns with resolutions of $26 \mathrm{~nm}$ in EUV resist system. ${ }^{13}$ Furthermore, the noria derivative with pendant oxetanyl groups was applicable as negative EUV resist material and showed clear line and space patterns with resolutions of $50 \mathrm{~nm}^{14}$

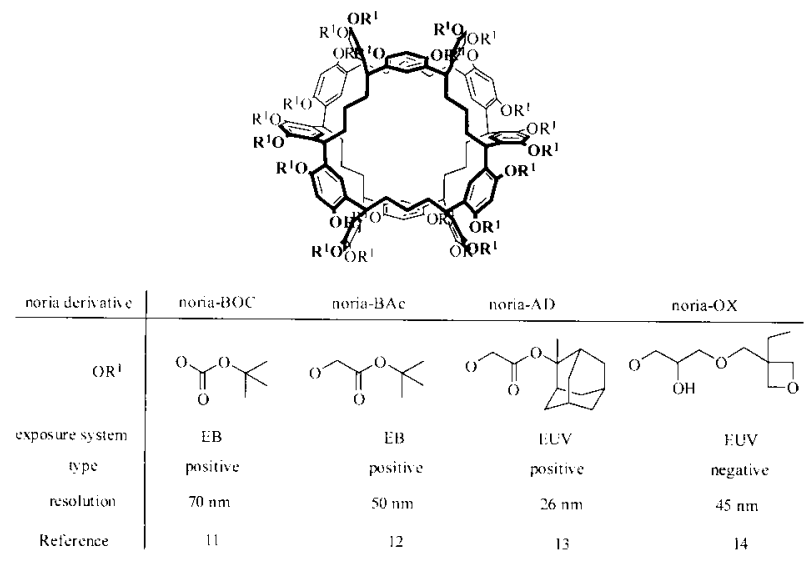

Scheme 1

In this paper, we examined the synthesis of noria derivative containing cyclohexyl acetal moieties and its application as an EUV-resist material.

\section{Experimental}

\subsection{Materials}

Tetrahydrofuran (THF) was dried over Na wire and purified by distillation before use. Other commercial organic solvents, pyridinium $p$-toluenesulfonate, trioctylamine, tetramethyl ammonium hydroxide (TMAH), triphenylsulfonium trifluoromethanesulfonate (TPS-TF), and triphenylsulfonium perfluorobutanesulfonate (TPS-PBF) were used without further purification. Cyclohexyl vinyl ether was donated from NIPPON CARBIDE INDUSTRIES Co., INC.

\subsection{Measurements.}

Infrared (IR) spectra were measured on a Thermo Electron Model NICOLET 380 spectrometer. The ${ }^{1} \mathrm{H}$ NMR spectra were recorded on JEOL Model JNM $\alpha-500(500 \mathrm{MHz}$ for ${ }^{1} \mathrm{H}$ NMR) instruments in DMSO- $d_{6}$ and $\mathrm{CDCl}_{3}$ using $\mathrm{Me}_{4} \mathrm{Si}$ (TMS) as an internal standard reagent for ${ }^{1} \mathrm{H}$ NMR. The number-average molecular weight $\left(M_{\mathrm{n}}\right)$ and molecular weight distribution $\left(M_{\mathrm{w}} / M_{\mathrm{n}}\right)$ of the polymers were estimated by size exclusion chromatography (SEC) with a Tosoh model HLC-8120 GPC equipped with refractive index and ultraviolet detectors using TSK gel columns (eluent THF, calibrated with narrow-molecular-weight polystyrene standards). Thermal analysis was performed on a Seiko Instruments thermogravimetric analyzer (TGA) Model EXSTAR6000/TG/DTA6200 at a heating rate of $10{ }^{\circ} \mathrm{C} / \mathrm{min}$ under nitrogen. The rate of photochemical deprotection reaction of the acetal moieties was measured by means of real-time IR (RT-IR) spectroscopy (BIO RAD model Excalibur FTS3000MX spectrometers).

\subsection{Synthesis of noria derivatives (noria-CHVE's).}

A mixture of noria $(34.1 \mathrm{~g}, 20 \mathrm{mmol})$ and cyclohexyl vinyl ether (CHVE) (102 mL, 720 $\mathrm{mmol})$ in THF $(150 \mathrm{~mL})$ was stirred for room temperature. After $2 \mathrm{~h}$, pyridinium $p$-toluenesulfonate $(3.62 \mathrm{~g}, 14 \mathrm{mmol})$ was added, and resulting mixture was stirred at room temperature for $12 \mathrm{~h}$. $\mathrm{NEt}_{3}(5.6 \mathrm{ml}, 40 \mathrm{mmol})$ and $\mathrm{CHCl}_{3}(500 \mathrm{~mL})$ was added and resulting solution was washed with saturated aqueous sodium hydrogen carbonate. The organic phase was dried over $\mathrm{MgSO}_{4}$ and concentrated in a rotary evaporator. The residue was dissolved in $\mathrm{CHCl}_{3}$, followed by precipitation from $n$-hexane to obtain a solid (noria-CHVE). The degree of introduction (DI) of cyclohexyl acetal moieties, calculated from the integration values of aromatic protons of the noria moiety at $5.85 \sim 8.07 \mathrm{ppm}$, as well as methine protons of noria moiety, methane protons of acetal moieties, and methine protons of the cyclohexyl moieties at $2.78 \sim 5.85 \mathrm{ppm}$, was found to be $50 \%$. Yield $21.6 \mathrm{~g}(42 \%)$. IR (film, $\left.\mathrm{cm}^{-1}\right): 3407(\mathrm{v} \mathrm{OH}), 2987,2982$, and 2856 $\left(v \mathrm{CH}_{2}\right), 1608$ and $1582(v \mathrm{C}=\mathrm{C}), 1023(v \mathrm{C}-\mathrm{O}-\mathrm{C})$, 981 ( $v$ O-C-O acetal moieties). ${ }^{1} \mathrm{H}$ NMR $(500$ $\left.\mathrm{MHz}, \mathrm{CDCl}_{3}, \mathrm{TMS}\right) \delta(\mathrm{ppm})=0.21 \sim 2.45(\mathrm{~m}$, $220 \mathrm{H}$, methylene protons of cyclohexyl moiety and $-\mathrm{CH}_{2}-\mathrm{CH}_{2}-\mathrm{CH}_{2}-$ of noria moiety, methyl protons of acetal moiety), $2.78-5.85(\mathrm{~m}, 43 \mathrm{H}$, methine protons of noria, acetal, and cyclohexyl moieties), $5.85-8.07(\mathrm{~m}, 24 \mathrm{H}$, aromatic $\mathrm{H})$. Other noria-CHVE's with various DI values of 59 and $91 \%$ were similarly synthesized by modifying the feed ratio and reaction time, as shown in Table 1. 
2.4 Photoinduced deprotection of noria-CHVE.

A solution of noria-CHVE ${ }_{50}(64 \mathrm{mg}, 0.02$ mmol) and TPS-TF (4.9mg, $5 \mathrm{~mol} \%$ ) as a photo-acid generator (PAG) in THF $(3 \mathrm{~mL}$ ) was cast on a $\mathrm{KBr}$ plate and dried in vacuo for $0.5 \mathrm{~h}$. The obtained film was irradiated with a $250 \mathrm{~W}$ high-pressure mercury lamp (Ushio Electric Co., $5 \mathrm{~mW} / \mathrm{cm}^{2}$ ) without a filter under nitrogen for 15 min at room temperature. The rate of decrease of cyclohexyl moieties was monitored with an RT-IR spectrometer at $980 \mathrm{~cm}^{-1}$ which was corresponding peaks of acetal moiety.

\subsection{Patterning ability.}

The patterning properties of noria-CHVE were examined as follows. A photo-resist was prepared from noria-CHVE, TPS-PBF as a photoacid generator $(10 \mathrm{wt} \%)$, trioctylamine as a quencher $(1.25 \mathrm{wt} \%)$, and PGMEA as the solvent. The photo-resist solution was filtered through a $0.5 \mu \mathrm{m}$ filter prior to evaluation. The resist sample was coated at $51 \mathrm{~nm}$ film thickness on a silicon wafer. The photo-resist film was baked (SB: Soft Bake), exposed, re-baked (PEB: Post Exposure Bake) and then developed with TMAH (2.38 wt \%) aqueous solution for approximately 30 seconds. All imaging exposures were made using the 0.3 numerical aperture (NA) small field exposure tool $(\mathrm{SFET})^{15}$ connected to a coater/developer track system ACT-12 in a chemically controlled environment. Patterns were observed using a critical-dimension scanning electron microscope (CD-SEM, S9380II, Hitachi).

\section{Results and discussion}

3.1 Synthesis of noria-cyclohexyl vinyl ether (noria-CHVE).

The noria derivatives (noria-CHVE's) with pendant cyclohexyl acetal moieties were synthesized by addition reaction of noria and cyclohyxyl vinyl ether in the presence of pyridinium $p$-toluenesulfonate as a catalyst in THF. By the control of the feed ratio and reaction time, noria-CHVE's with various degrees of introduction of cyclcohexyl acetal moieties (DI) $=50 \sim 91 \%$ were synthesized (Scheme 2). These conditions and results are summarized in Table 1.

The structure of noria-CHVE's was confirmed by IR and ${ }^{1} \mathrm{H}$ NMR spectroscopy. Figure 1 depicts the 'H NMR spectrum of noria-CHVE 50 (run 1 in Table 1), along with that of noria. The spectrum shows new peaks assignable to methylene protons and methine protons of the cyclohexyl acetal moiety at $0.21-2.45 \mathrm{ppm}$ and $2.78-5.85 \mathrm{ppm}$, respectively, and indicated that the reaction of noria and cyclohexyl vinyl ether proceeded to give acetal moieties.i.e., the noria derivative with pendant cyclcohexyl moiety was obtained. The degree of introduction of cyclo-
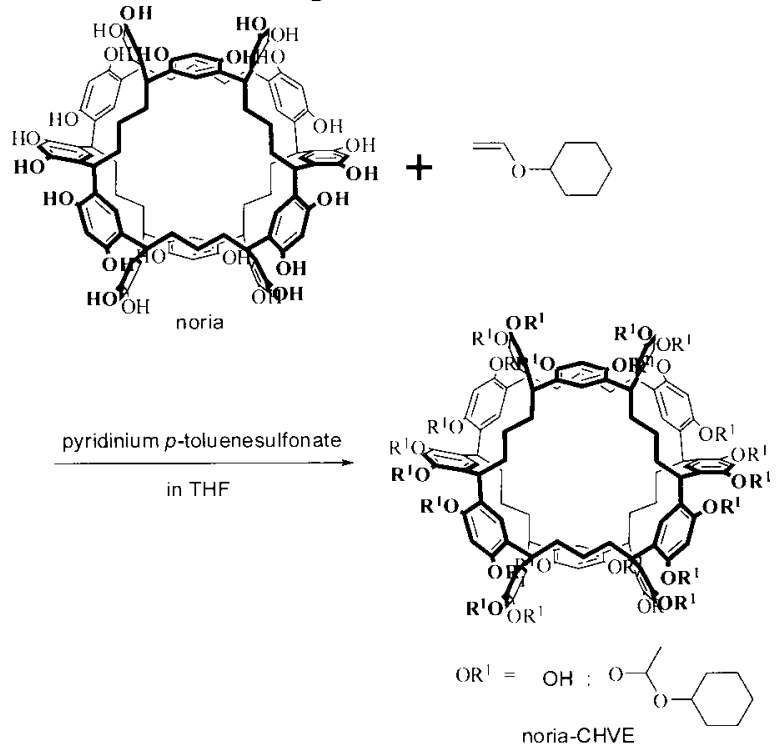

Scheme 2

hexyl moiety (DI) was calculated from the integration ratios of aromatic protons of noria moiety at $5.85 \sim 8.07 \mathrm{ppm}$, and the methine protons of the noria moiety, acetal moiety, and cyclohexyl moiety at $2.78-5.85 \mathrm{ppm}$ in the ${ }^{1} \mathrm{H}$ NMR spectrum, and was $50 \%$. We could synthesize noria-CHVE's with DI's $=50 \sim 91 \%$

Table 1. The synthesis of noria-CHVE's ${ }^{\mathrm{a}}$

\begin{tabular}{ccccccccc}
\hline \multirow{2}{*}{ Run } & feed ratio & $\begin{array}{c}\text { reaction } \\
\text { time }(\mathrm{h})\end{array}$ & $\begin{array}{c}\text { noria } \\
\text { derivative }\end{array}$ & D.I $^{\mathrm{b}}$ & $\begin{array}{c}\text { Yield }^{\mathrm{c}} \\
(\%)\end{array}$ & $M_{\mathrm{n}}{ }^{\mathrm{d}}$ & $M_{\mathrm{w}} / M_{\mathrm{n}}{ }^{\mathrm{d}}$ & $T^{\mathrm{dic}}$ \\
\hline 1 & noria $/ \mathrm{CHVE}=1 / 1.5$ & 12 & noria-CHVE $_{50}$ & 50 & 42 & 2360 & 1.04 & 112 \\
2 & noria $/ \mathrm{CHVE}=1 / 2$ & 12 & noria-CHVE $_{59}$ & 59 & 42 & 2540 & 1.03 & 121 \\
3 & noria $/ \mathrm{CHVE}=1 / 2$ & 6 & noria-CHVE $_{91}$ & 91 & 41 & 2650 & 1.03 & 135 \\
\hline
\end{tabular}

${ }^{\mathrm{a}}$ The reaction of noria and CHVE was carried out in the presence of pyridinium $p$-toluenesulfonate in THF at room temperature. ${ }^{b} \mathrm{C}$ alculated by ${ }^{1} \mathrm{H}$ NMR. ${ }^{\mathrm{c}}$ Methanol insoluble part. ${ }^{\mathrm{d}}$ Estimated by SEC (eluent; THF). $\quad{ }^{\mathrm{e}} T^{\mathrm{di}}=$ The initial thermal decomposition temperature determined by TGA. 
by appropriately adjusting the feed ratio and reaction time (Table 1). Number-average molecular weight $\left(M_{\mathrm{n}}\right)$, weight-average molecular weight $\left(M_{\mathrm{w}}\right)$, and polydispersity ratio $\left(M_{\mathrm{w}} / M_{\mathrm{n}}\right)$ were also determined by means of SEC. Although the values of $M_{\mathrm{n}}$ and $M_{\mathrm{w}}$ of noria-CHVE's (DI $=50,59$, and 91\%) increased with increasing value of DI. However, the values of $M_{\mathrm{w}} / M_{\mathrm{n}}$ were all the same $(1.03 \sim 1.04)$, i.e., the reaction can be controlled very precisely.
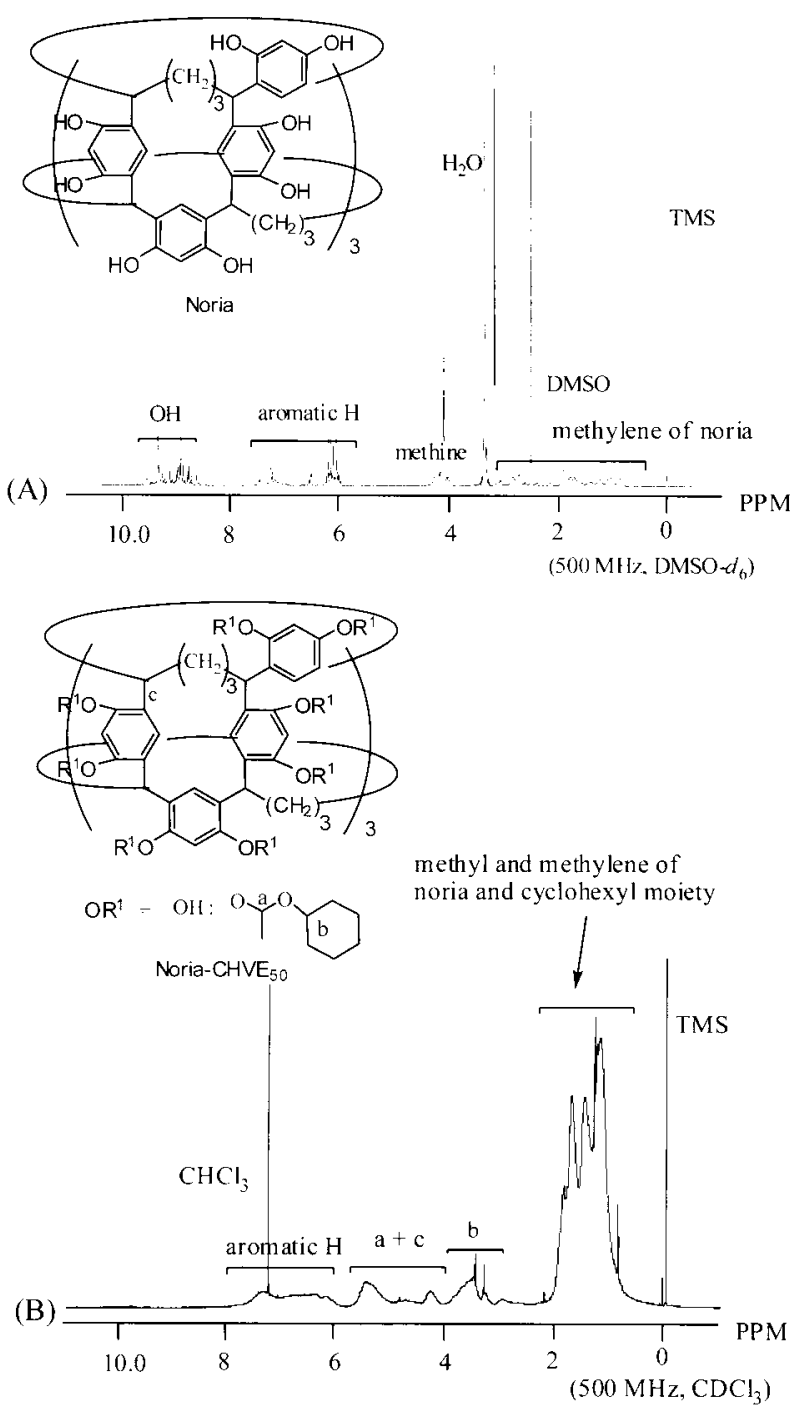

Figure 1. ${ }^{1} \mathrm{H}$ NMR spectra of noria and noria-CHVE 50 . (A) noria (500 MHz, DMSO- $\left.d_{6}\right)$.

(B) noria- $\mathrm{AD}_{50}(\mathrm{DI}=50 \%)\left(500 \mathrm{MHz}, \mathrm{CDCl}_{3}\right)$.

3.2 Physical properties (solubility, film-forming ability, and thermal stability) of noria-CHVE's.

The physical properties of noria-CHVE's were examined relevant to application as EUV-resist materials.

\subsection{Solubility.}

Table 3 summarizes the characteristics solubility of noria-CHVE's (DI $=50,59$, and $91 \%$ ) and noria. Noria was soluble in TMAH aqueous solution, whereas all noria-CHVE's were insoluble. This means that noria-CHVE's can be applicable to alkali-developable resist material. In the case of polyethylene glycol monomethyl ether (PGME), noria-CHVE 50 and noria- $\mathrm{CHVE}_{59}$ were soluble, while noria- $A D_{91}$ was soluble in part. These results indicate that noria- $\mathrm{CHVE}_{50}$ and noria-CHVE $\mathrm{C}_{59}$ might be suitable as EUV-resist materials.

\subsection{Film-forming ability.}

The film-forming ability of noria-CHVE's (DI $=50,59$, and $91 \%$ ) was examined by spin coating a solution of noria or noria-CHVE's $50 \mathrm{mg}$ in poly(ethylene glycol) methylether acrylate (PEGMEA) $1.0 \mathrm{ml}$ on a silicon wafer, and drying the wafer in vacuo at room temperature. All noria-CHVE's had good film forming property with high transparency.

\subsection{Thermal stability.}

The thermal decomposition of noria-CHVE's was measured by means of TGA. Decomposition started in the range of $112 \sim 137$ ${ }^{\circ} \mathrm{C}$, as summarized in Table 1 . It was observed that the thermal stability increased with increasing the values of DI of synthesized noria-CHVE's. This might be because acidic phenol groups had been replaced with acetal groups, i.e., acidic phenol groups might promote the thermal decomposition reaction of noria-CHVE's. However, we expected that the remaining hydroxyl groups of noria-CHVE result in higher hydrophilicity and thus provide good adhesion to the substrate.

As the result, we considered that noria- $\mathrm{CHVE}_{50}$, and noria-CHVE 59 are good candidates for EUV-resist materials.

3.6 Photoinduced deprotection reaction of noria-CHVE.

The photoinduced deprotection of films prepared with $5 \mathrm{~mol} \%$ of TPS-TF as a photoacid generator was carried out under UV irradiation with a $250 \mathrm{~W}$ high-pressure mercury lamp. Figure 2 depicts the RT-IR spectra during the exposed with UV of noria-CHVE 50 (run 1 in Table 1). Before the deprotection reaction, a peak at around $980 \mathrm{~cm}^{-1}$ was seen, assignable to the stretching vibration of $\mathrm{O}-\mathrm{C}-\mathrm{O}$ of acetal moiety (Figure 2 [a]). After heating for $1 \mathrm{~min}$, a 
Table 2 . The solubility of noria-CHVE

\begin{tabular}{|c|c|c|c|c|}
\hline Solvent & noria & noria-CHVE ${ }_{50}$ & noria-CHVE $_{59}$ & noria-CHVE $\mathrm{C}_{91}$ \\
\hline water & - & - & - & - \\
\hline DMSO & ++ & - & +- & - \\
\hline DMAc & ++ & ++ & +- & +- \\
\hline DMF & +- & +- & +- & +- \\
\hline Acetonitrile & - & - & - & - \\
\hline Methanol & - & - & - & - \\
\hline 2-Propanol & - & +- & +- & +- \\
\hline 1,4-Dioxane & - & ++ & ++ & ++ \\
\hline THF & - & ++ & ++ & ++ \\
\hline Acetone & - & ++ & ++ & + \\
\hline Methyl ethyl ketone & - & ++ & +- & ++ \\
\hline$o$-Dichlorobenzene & - & ++ & ++ & ++ \\
\hline Ethyl acetate & - & ++ & ++ & ++ \\
\hline Ethyl ether & - & ++ & ++ & ++ \\
\hline Chloroform & - & ++ & ++ & ++ \\
\hline Anisol & - & ++ & ++ & ++ \\
\hline Chlorobenzene & ++ & ++ & ++ & ++ \\
\hline Toluene & - & ++ & ++ & ++ \\
\hline Cyclohexanone & - & + & ++ & ++ \\
\hline$n$-Hexane & - & - & +- & ++ \\
\hline PGMEA $^{\mathrm{a}}$ & - & ++ & ++ & ++ \\
\hline PEGME $^{b}$ & - & ++ & ++ & + \\
\hline $\begin{array}{l}\mathrm{TMAH}^{\mathrm{c}}(2.38 \mathrm{wt} \%) \\
\text { a.q. }\end{array}$ & ++ & - & - & - \\
\hline Film-forming ability & $x$ & $\circ$ & o & o \\
\hline
\end{tabular}

${ }^{a}$ Poly(ethylene glycol) methylether acrylate (PEGMEA).

${ }^{\mathrm{b}}$ Polyethylene glycol monomethyl ether (PEGME).

${ }^{\mathrm{c}}$ Tetramethyl ammonium hydroxide (TMAH).

new broad peak appeared at around $3300 \mathrm{~cm}^{-1}$, which was assignable to the stretching vibration of hydroxy groups (Figure2 [B]). This result shows that the deprotection reaction of acetal moieties proceeded, to produce noria. The peak at $980 \mathrm{~cm}^{-1}$ due to O-C-O of acetal moieties decreased during the exposure. From the change of this peak, it is possible to calculate the conversion of the photoinduced deprotection reaction, and after $15 \mathrm{~min}$, the conversion rate was calculated to be $94 \%$ (Figure 2 [E]).
Furthermore, the resulting product was soluble in 2.38 $\mathrm{wt} \%$ TMAH aqueous solution The conversions of noria- CHVE's (DI $=59$ and 91) were similarly calculated to reach 94 and $93 \%$, respectively. This means that the noria-CHVE's are good candidates for positive-type working resist materials.

3.7 Patterning properties of noria-CHVE.

In our previous report, we examined the synthesis and patterning property in EUV system of noria derivatives noria-AD with pendant adamantate groups. As the result, noria- $\mathrm{AD}_{23}$ with $\mathrm{DI}=$ $23 \%$ provided a more clear line and space pattern with a resolution of $26 \mathrm{~nm}$ compared to that of noria- $\mathrm{AD}_{44}$ with $\mathrm{DI}=44 \%$. This indicated that noria-AD with lower DI of adamantate groups would achieve higher resolution. In this time, we examined the patterning properties of the films prepared from noria-CHVE 59 and noriaCHVE $_{50}$.

Figure 3 (A) depicts the clear patterns in the case of the mask size at $45 \mathrm{~nm}$ obtained with noria$\mathrm{CHVE}_{59}$ and noria-CHVE $\mathrm{C}_{50}$, using trioctylamine as a quencher at $90{ }^{\circ} \mathrm{C}$ soft bake (SB) temperature and $90{ }^{\circ} \mathrm{C}$ post exposure bake (PEB) temperature. In the case of noria-CHVE 59 , a $45.3 \mathrm{~nm}$ resolution pattern with LER $=8.0 \mathrm{~nm}$ could be obtained using a exposure dose $=17.0 \mathrm{~mJ} / \mathrm{cm}^{2}$. Noria-CHVE $_{50}$ showed that a $45.6 \mathrm{~nm}$ resolution pattern with LER $=6.9 \mathrm{~nm}$ could be obtained using a exposure dose $=14.5 \mathrm{~mJ} / \mathrm{cm}^{2}$ (Figure 3 [A]).

This means that noria-CHVE 50 had higher potential to offer higher resolution patters, due to that a pattern at $45 \mathrm{~nm}$ mask could be achieved 
with lower exposure dose and lower LER compared to those of noria-CHVE $\mathrm{C}_{59}$. We next examined 40,35, and $32 \mathrm{~nm}$ sizes of mask in EUV resist system. These results are depicted in Figure 3 (B), (C), and (D). Clearly resolved patterns at $37.9 \mathrm{~nm}$ with LER $=7.2 \mathrm{~nm}$ could be obtained with noria-CHVE 50 . This indicates that noria derivatives with lower DI of cyclohexyl moieties would achieve higher resolution.i.e., the critical value of DI in noria-CHVE might be lower than $50 \%$. It seems that critical point is dramatically solubility change point upon photodeprotection, offering both higher photosensitivity and higher pattern resolution.

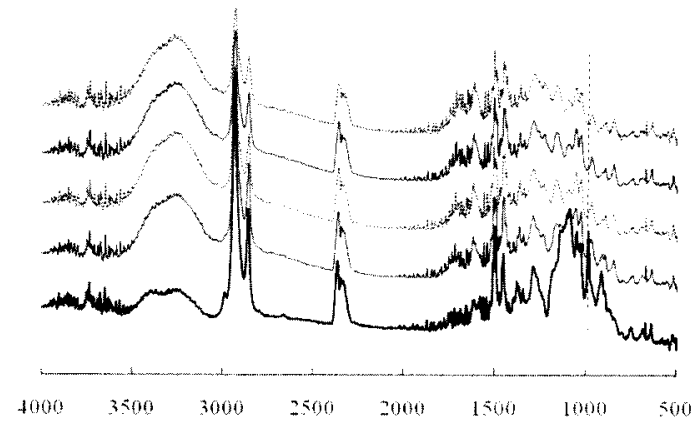

Figure 2. RT-IR spectra of noria-CHVE 50 before and after photoirradiation. (A) noria-CHVE $\mathrm{CHO}_{50}$ (B) After 1 min. (C) After 5 min. (D) After 10 min. (E) After $15 \mathrm{~min}$.

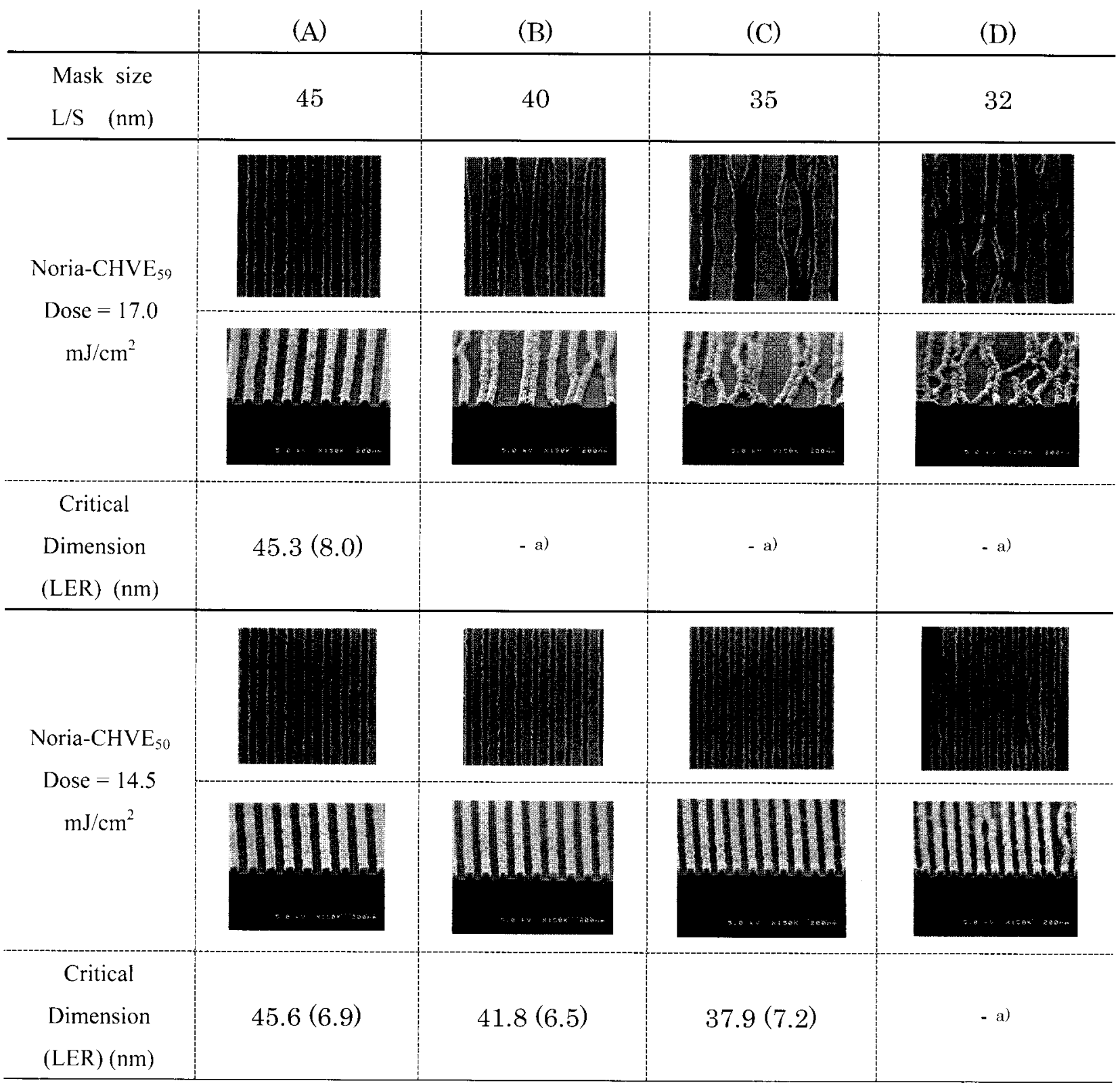

Figure 3. EUV-resist patterns obtained with noria-CHVE $\mathrm{CH}_{50}$ and noria-CHVE $\mathrm{CH}_{9}$ at various exposure doses at $32 \sim$ $45 \mathrm{~nm}$ mask sizes. (A) Mask size $=45 \mathrm{~nm}$. (B) Mask size $=40 \mathrm{~nm}$. (C) Mask size $=35 \mathrm{~nm}$. (D) Mask size $=32 \mathrm{~nm}$. a) Not determined. 


\section{Conclusion}

The synthesis, physical properties, and EUV-resist properties of noria derivatyives (noria-CHVE's ) with pendant cyclochexyl acetal moieties were examined. The noria-CHVE's was synthesized by the reaction of noria and cyclohexyl vinyl ether and their values of degree of introduction (DI) of acetal moieties were controlled by the adjustment of feed ratios and reaction time. i.e. DI $=50,59$, and $91 \%$. It was showed that all noria-CHVE's had good physical properties for application as resist materials. Noria- $\mathrm{CHVE}_{50}$ and Noria- $\mathrm{CHVE}_{59}$ provided clear line and space patterns of $37.9 \mathrm{~nm}$ resolution pattern with LER $=7.2 \mathrm{~nm}$ and $45.3 \mathrm{~nm}$ resolution pattern with LER $=8.0 \mathrm{~nm}$, respectively. These results showed that noria-CHVE's had high potential as next-generation EUV-resist materials, and noria-CHVE's with lower DI would achieve higher resolution.

\section{Acknowledgement.}

This work was supported by Nano-Space Chemistry for the Creation of Functional Materials at Kanagawa University.

\section{References}

1. (a) H. Ito, In Radiation Curing in Polymer Science and Technology; Fouassie, J. P. and Rabek, J. F. Eds.; Elsevier: London, vol 4, (1993) p. 237. (b) A. Macdonard, C. G. Willson, J. M. J. Fréchet, Acc. Chem. Res., 27, (1994) 151. (c) H. Ito, N. Seehof, R. Sato, T. Nakayama, M. Ueda, In Micro- and Nano-Patterning Polymers; H. Ito, E. Reichmanis, O. Naramasu, and T. Ueno, Eds.; American Chemical Society : Washington, DC, (1998) p. 208. (d) K. Toyota, S. Okazaki, Eds.; Development and Application of Extreme Ultraviolet Light Source, CMC: Tokyo (2007).

2. (a) M. Yoshiiwa, H. Kageyama, F. Wakaya, M. Takai, K. Gamo, Y. Shirota, $J$. Photopolym. Sci. Tech. 9, (1996) 57. (b) O. Haba, K. Haga, M. Ueda, Chem. Mater. 11, (1999) $427 . \quad$ (c) T. Fujigaya, Y. Shibasaki, M. Ueda, J. Photopolym. Sci. Tech., 14, (2001) 275. (d) J. Dai, S. W. Chang, A. Hamad, D. Yang, N. Felix, C. K. Ober, Chem. Mater. 18, (2006) 3404. (e) T. Kadota, H. Kageyama, F. Wakaya, K. Gamo, Y. Shirota, Chem. Lett. 33, (2004) 706. (f) T. Nakayama, K. Haga, O. Haba, M. Ueda, Chem. Lett. (1997) 265. (g) J. B. Kim, H. J. Jun, Y. G. Kwon, Chem. Lett. 10, (2002) 1064. (h) R. A. Lawson,C. T. Lee, R. Whetsell, W. Yueh, J. Roberts, L. Tolbert, C. L. Hernderson, SPIE 6519,(2007) 65191N. (i) R. A. Lawson, C. T. Lee,
W. Yueh, J. Roberts, L. Tolbert, C. L. Hernderson, SPIE 6923, (2008) 69230K. (j) I. Takemoto, N. Ando, K. Edamatsu, Y. Lee, M. Takashima, H. Yokoyama, H. SPIE 6923, (2008) 69231N. (k) J. Fujita, Y. Ohnishi. Y. Ochiai, S. Matui, Appl. Phys. Lett., 68, (1996) 1297.

3. (a) J. Fujita, Y. Ohnishi. S. Manako, Y. Ochiai, E. Nomura, T. Sakamoto, S. Matsui, Jpn. J. App. Phys., 36, (1997) 7769. (b) T. Sakamoto, S. Manako, J. Fujita, Y. Ochiai, T. Baba, H. Yamamoto, T. Teshima, Appl. Phys. Lett., 77, (2000) 301. (c) M. Ishida, J. Fujita, T. Ogura, Y. Ochiai, E. Ohshima, J. Momoda, Jpn. J. Appl. Phys., 42, (2003) 3913. $\quad$ (d) K. Takeshi, R. Nakayama, M. Ueda, Chem. Lett., 27, (1998) 865. (e) K. Young-Gil, J. B. Kim, T. Fijigaya, Y. Shibasaki, M. Ueda, J. Mater. Chem., 12, (2002) 53. (f) M. Ueda, D. Takahashi, T. Nakayama, O. Haba, Chem. Mater., 10, (1998) 2230. (g) T. Nakayama, D. Takahashi, K. Takeshi, M. Ueda, $J$. Photopolym. Sci. Tech., 12, (1999) 347. (h) Y. Ochiai, S. Manako, H. Yamamoto, T. Teshima, J. Fujita, E. Nomura, J. Photopolymer. Sci. Tech. 13, (2000) 413.

4. (a) T. Hirayama, D. Shiono, S. Matsumaru, T. Ogata, H. Hada, J. Onodera, T. Arai, T. Sakamizu, A. Yamaguchi, H. Shiraishi, H. Fukuda, M. Ueda, Jpn. J. Appl. Phys. 44, (2005) 5484. (b) A. D. Silva, N. Felix, J. Sha, J. K. Lee, C. K. Ober, SPIE 6923, (2008) 69231L.

5. (a) T. Tada, T. Kakayama, Jpn. J. Appl. Phys., 35, (1996) L63. (b) J. Wang, Y. Shen, S. Kessel, R. Fernandes, K. Yoshida, S. Yagai, D. G. Kurth, H. Mohwald, T. Nakanishi, Angew. Chem. Int. Ed., 48, (2009) 2166.

6. M. Iyo, K. Tsutsui, A. Kameyama, T. Nishikubo, J. Polym. Sci. Part A: Polym. Chem. 37, (1999) 3071.

7. H. Kudo, K. Mitani, T. Nishikubo, M. Masaya, T. Miyashita, Bull. Chem. Soc. Jpn., 77, (2004) 819 .

8. H. Kudo, K. Mitani, S. Koyama, T. Nishikubo, Bull. Chem. Soc. Jpn., 77, (2004) 2109.

9. T. Nishikubo, The $88^{\text {th }}$ Annual Meeting of Chem. Soc. Jpn., (2008) 1C2-20.

10. H. Kudo, R. Hayashi, K. Mitani, N. C. Kasuga, T. Nishikubo, Angew. Chem. Int. Ed. 45, (2006) 7948 .

11. (a) X. André, J. K. Lee, A. DeSilva, C. K. Ober, H. B. Cao, H. Deng, H. Kudo, D. Watanabe, T. Nishikubo, SPIE 6519, (2007) 65194B. (b) M. Tanaka, A. Rastogi, H. Kudo, D. Watanabe, T. Nishikubo, C. K. Ober, J. Mater: Chem., 19, (2009) 4622. 
12. H. Kudo, D. Watanabe. T. Nishikubo, K. Maruyama, D. Shimizu, T. Kai, T. Shimokawa, C. K. Ober, J. Mater. Chem. 18, (2008) 3588.

13. (a) T. Nishikubo, H. Kudo, Y. Suyama, H. Oizumi, T. Itani, J. Photopolym. Sci. and Tech. 22, (2009) 73. (b) H. Kudo, Y. Suyama, T. Nishikubo, H. Oizumi, T. Itani, J. Mater. Chem., submitted (2010).

14. H. Seki, Y. Kato, H. Kudo, H. Oizumi, T. Itani, T. Nishikubo, Jpn. J. Appl. Phys. in press (2010).

15. K. Tawarayama, S. Magoshi, . Tanaka, S. Shirai, H. Tanaka, Jpn. J. Appl. Phys. 47, (2008) 4866. 